\title{
Fundamental Design of Flood Management Educational Games Using Virtual Reality Technology
}

\author{
https://doi.org/10.3991/ijoe.v18i03.27787

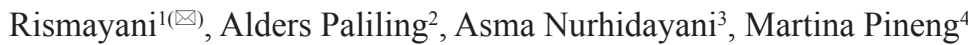 \\ ${ }^{1}$ Department of Software Engineering, Dipa Makassar University, Makassar, Indonesia \\ ${ }^{2}$ Sembilan Belas November Kolaka University, Kolaka, Indonesia \\ ${ }^{3}$ Puangrimaggalatung University, Sengkang, Indonesia \\ ${ }^{4}$ Kristen Indonesia Toraja University, Toraja, Indonesian \\ rismayani@undipa.ac.id
}

\begin{abstract}
The geographical location of Makassar, which is included in the lowlands and the increasingly uncertain climate change, makes this area included in the flood map in Indonesia. Almost every year, the city of Makassar is haunted by the potential for flooding in several vulnerable areas such as the sub-districts of Manggala, Wajo and Bontoala and the Antang National Housing, every disaster in the city of Makassar is handled by the Regional Office. Disaster Management Agency. So far, flood disaster preparedness is still not responsive to a disaster, most of them sit around waiting for help, and the community lacks understanding of what to do when a flood disaster hits them. This study aims to design a system that provides education to the public about flood disaster management using virtual reality technology. This research method uses Virtual Reality technology based on educational games. The result of this research is the existence of a flood control simulation system that can help the people of Makassar understand what to do in the event of a flood and with virtual reality-based, educational game technology providing a more attractive appearance. So that people are happy and happy to use educational games. Based on black-box testing, valid results were obtained for all functional tests on the flood prevention educational game simulation system, especially in Makassar. Then based on the results of a questionnaire to determine the system's benefits obtained from fifty respondents consisting of children, adolescents and adults, the outcomes received $91.3 \%$ stated very useful, $5.2 \%$ useful, $3.5 \%$ quite helpful and $0 \%$ useless.
\end{abstract}

Keywords - game, flood, management, virtual reality, education

\section{Introduction}

Makassar City is the capital city of South Sulawesi province. The area of Makassar city is $199.26 \mathrm{~km}^{2}$. The geographical location of Makassar City is $5^{\circ} 8^{\circ} \mathrm{N} 119^{\circ} 25^{\prime} \mathrm{E}$. Makassar is located on the southwest coast of the island of Sulawesi and the Makassar Strait in the west, Pangkajene Islands Regency in the north, Maros in the east and Gowa in the south. The geographical location of Makassar, which is included in the lowlands and the increasingly uncertain climate change, makes this area included in the flood 
map in Indonesia. Almost every year, Makassar City is haunted by the potential for flooding in several vulnerable areas such as Manggala, Wajo and Bontoala Regencies. Makassar City Disaster Management Agency is a non-departmental government agency that carries out disaster management tasks in the Makassar City area based on policies established by the National Disaster Management Agency. So far, community preparedness for flood disasters is still not responsive. Most people sit quietly, waiting for help to arrive. There is a lack of public understanding of what to do when affected by a flood disaster. That way, the community needs education about flooding to know better what needs to be done quickly and precisely.

The problem in this research is how to create a system that can educate the people of Makassar about flood management, apply Virtual Reality technology into a flood disaster management simulation system, and build a game-based flood disaster management system in the city of Makassar.

The purpose of this study is to create a system that can educate the people of Makassar about flood management, implement Virtual Reality technology into a flood disaster simulation system and build an educational game-based system for flood disaster management in the city of Makassar.

The benefits of this research are that it can educate the people of Makassar about flood management, implement Virtual Reality technology into a flood disaster management simulation system, and build an educational game-based system for flood disaster management in the city of Makassar, Indonesian.

\section{$2 \quad$ Literature review}

\subsection{Educational game}

Educational games are games designed to help people learn certain subjects, expand concepts, reinforce developments, understand historical events or cultures, or help them learn skills while playing. Educational games are games that are explicitly designed for educational purposes or have incidental or secondary educational value. Game types include board games, card games and video games[1].

\section{$2.2 \quad$ Flooding}

Flooding is the spread of water that submerges the soil, which is generally dry. In "graceful water" wisdom, the word may also be practical for the entry of the tide. Floods are part of the study of hydrological regulations and are very disturbing in agriculture, civil engineering and public health[2].

\subsection{Virtual reality}

Virtual Reality (VR) is a simulated experience that can be similar to or completely different from actual. Virtual reality applications may include entertainment and educational purposes - other, various types of VR style technology, including augmented reality and mixed reality[3]. Currently, standard virtual reality systems use virtual 
reality headsets or multi-projection environments to produce realistic images, sounds, and other sensations that simulate the user's physical presence in the virtual environment. A person using virtual reality equipment can look around the artificial world, move within it, and interact with virtual features or items. The effect is usually created by a VR headset consisting of a head-mounted screen with a small screen in plain sight, but it can also be made through a specially designed room with multiple large screens. Virtual reality typically combines auditory and video feedback and allows other sensory and involuntary feedback via cardiac technology. Therefore every VR has various components to create this illusion, and which are the most important:

- Head Mounted Display (HMD), this is an essential component of VR. This serves to deceive our eyesight. VR systems use the principle of stereoscopic vision to simulate our perspective of 3D depth and structure. To achieve this, the VR system must generate a separate image for each eye.

- Display, VR system creates a stereoscopic image on the HMD screen at a minimum of $60 \mathrm{fps}$.

- Optics, HMD also comes with a pair of lenses. This lens serves to focus the image seen by the eye.

\section{$2.4 \quad$ Related work}

A study conducted by Ming-Chang Wen et al. in 2013 under the title "Feldouocadtigoanm1 E: Alternative Approaches to Disasters" the discussion presented an ongoing disaster education project for disaster education in which we designed a flood game that allowed high school students to play a decision-making role[4]. Ferran Argelaguet conducted a follow-up study in 2013 with the title "A survey of 3D object selection technique for the virtual environment", which discussed surveys of 3D object selection techniques. The findings in the human control model analyze the main factors that affect the selection performance and classify the existing methods according to several criteria. Application user interface components, designation techniques require close connection with the rendering pipeline, introduce new elements for drawing, and potentially modify object layouts, and the way scenes are rendered[5]. Further research was conducted by Meng-Han Tsai et al. 2015. The title "Game-based education for disaster prevention" discusses the development of flood games to encourage active learning through exploration. Game design is based on "Shikakeology" and "game-initiated learning" methods[6]. Research conducted by Petersen et al. in 2015 under the title "Cognitive Augmented Reality" discussed the introduction of the concept of Cognitive Augmented Reality, which radically revises the existing approach to AR-based assistance systems and proposes a new paradigm that utilizes prior visual observation and complete manipulative workflow learning[7]. This study was conducted by Matthew Barr et al. in 2017 with the title "Video games can develop graduate skills in higher education students: A randomized trial" discussed findings showing that game-based learning interventions have a role in higher education[8]. The study was conducted by Praiwattana et al. in 2017 under the title "Game-Based Crisis Simulation and Generation Framework: Implementation Design and Structure" discussed the implementation 
options of a standard framework tool design to represent the scope of different fields, resources, stakeholders, and crisis scenario structures using Unity3D game engine technology[9]. Rismayani and Andi Irmayana conducted a study in 2017 with the title "Implementation of e-learning on the subject of mobile-based interactive data structures", discussing the development of learning methods, namely mobile-based data structures where students can access materials, references and applications related to subjects without being limited. by place and time, whenever and wherever you are[10]. This study was conducted by Phungphat et al. in 2018 under the title "Lord of Secure: Virtual Reality Game to Educate Network Security" discussing motivating and helping students to see better than in traditional classrooms, we proposed a security game called "Lord of Secure", which is virtual reality (VR) games on Android for education. As an alternative teaching material for students to gain knowledge about network security effectively (Visoottiviseth et al., 2018). Research conducted by Qin Nan and Ma Liang in 2018 with the title "Sub Safe-A Game-Based Training System for Submarine Safety" discusses Sub Safe's background and primary functions. An evaluation of the effectiveness of the training and some enlightenment is also presented[11]. The study was conducted by Qiong Liu et al. in 2019 with the title "The influence of environmental education on environmental ethics and literacy based on virtual reality technology" discussed the proposed ways and appropriate methods to strengthen environmental moral education based on scientific research methods, rigorous scientific theory and specific content of environmental moral education[12]. Research conducted by Makransky in 2019 with the title "Motivational and Cognitive Benefit of Training in Immersive Virtual Reality-Based on Multiple Assessments" discusses this research to test the effectiveness of immersive virtual reality (VR) as a medium for delivering laboratory safety training[13]. The study was conducted by Mokhtar et al. The year 2019 with the title "Preliminary Study: Flood Alert Preparation Training Using Serious Games" discusses the presentation of an analysis of flood awareness training preparations among Malaysians, the existing methods in disseminating flood awareness information and the need for technology to prepare for flood awareness training from the perspective of experts[14]. This study was conducted by Weiss et al. in 2019 under the title "Large crowd position-based real-time simulation" discussed introducing crowd simulation methods that run at an interactive level for orders of one hundred thousand agents, making it very suitable for use in games[15]. Furthermore, Adli et al. conducted educational games to increase awareness and preparedness against floods, an educational game called WASIBAN (Waspada and Siaga Flood). The system was created so that people could take preventive measures[16].

\section{$3 \quad$ Method and material}

\subsection{Research location}

The location or place of the study took the object of Regional Housing in Manggala, Wajo, Bontoala and Antang Regencies. The area of data collection and data collection is in Makassar City, South Sulawesi Province, and Indonesian. 


\subsection{Stage of the research}

- The Observation: The researcher first observes the research location.

- Data Collection: collect information from the research site.

- Data Analysis: breaking the entire information system into its parts to identify and evaluate problems, opportunities, obstacles that occur and the expected needs so that improvements can be proposed.

- Design: There are architectural design activities and educational game applications for flood disaster simulations in this process.

- Creating an educational game simulation system: strategies to solve problems and develop the best solution by compiling a code for an educational game simulation system for flood disaster management.

- System Testing: knowing how the designed application works according to specifications and assessing whether each designed function or procedure is free from errors.

- Implementation: the application of the modelling system made to be applied to users, namely the people of Makassar, especially areas affected by floods in every rainy season.

\subsection{Tools and material}

The Tools and materials for this research are:

- Tools: PC Device, Mouse Logitech K150, RAM 32GB Android Smartphone 4GB Internal, Windows 10, Microsoft Word 2007, Android Studio 2017, Star UML, Mozilla Firefox, Unity engine 2018.1.

- Material: Documents were containing data on flood response actions, Flood Location Area Data, Flood Information

- Conceptual Design Tools: in this research activity, the author uses tools in analyzing and studying the existing system and the system to be designed. The instrument used is the UML (Unified Modeling Language) system chart, namely: Use Case Diagram, Sequence Chart, and Activity Diagram.

\subsection{Data Source}

The Sources of research data obtained as follows:

- Primary data is data in the form of data related to virtual reality technology and games and those related to flood disaster management.

- Secondary data in the form of literature, articles and several references related to virtual reality technology and games, and those related to flooding disaster management. 


\subsection{Architecture System}

Figure 1 describes the system architecture where the people of Makassar city can use smartphones/android devices to play educational games based on a flood disaster management simulation system, the technology used in Virtual Reality with three levels of game levels.

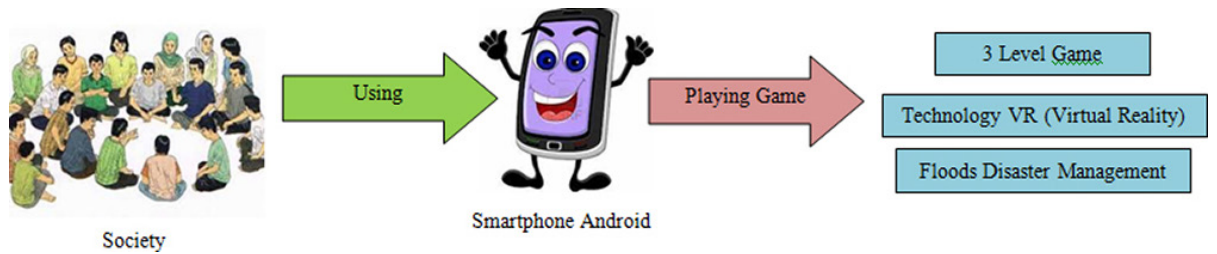

Fig. 1. Architecture system

\subsection{Design system}

Figure 2 explains the use case diagram of the system, which is a general description of the system; there is one actor, namely the user/community affected by the flood in the game, there are activities to start the game, choose the level of the game, dame information and display the score of the game.

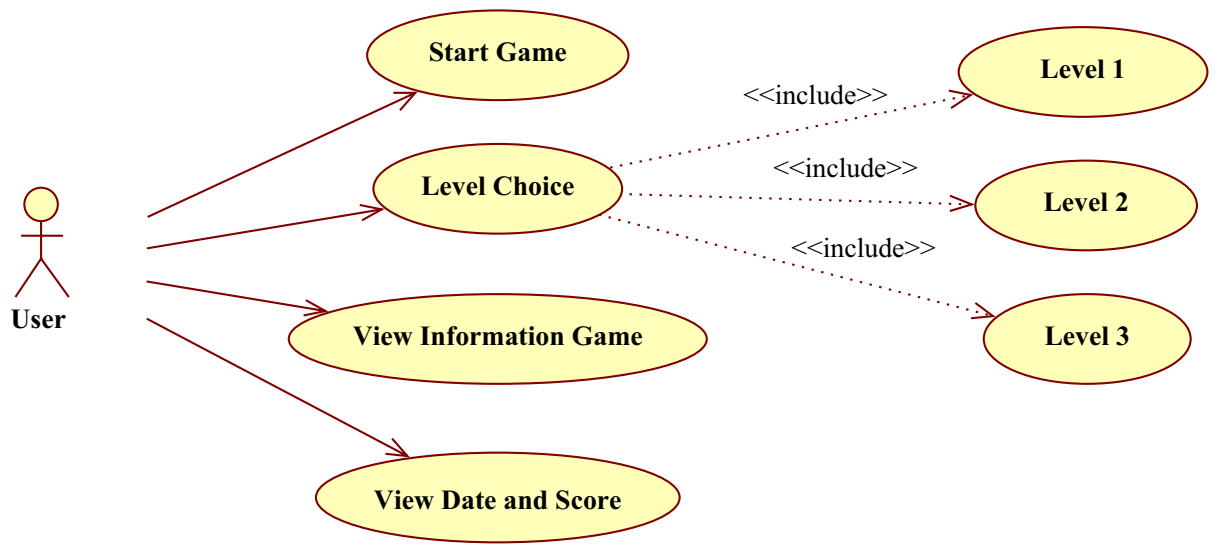

Fig. 2. Architecture system

Figure 3 design using a sequence diagram or diagram of an actor's activity with the object of a game-based flood disaster management simulation education system using virtual reality technology. 
Figure 4 illustrates an activity system diagram that describes using a game-based flood disaster management simulation education system using virtual reality technology.

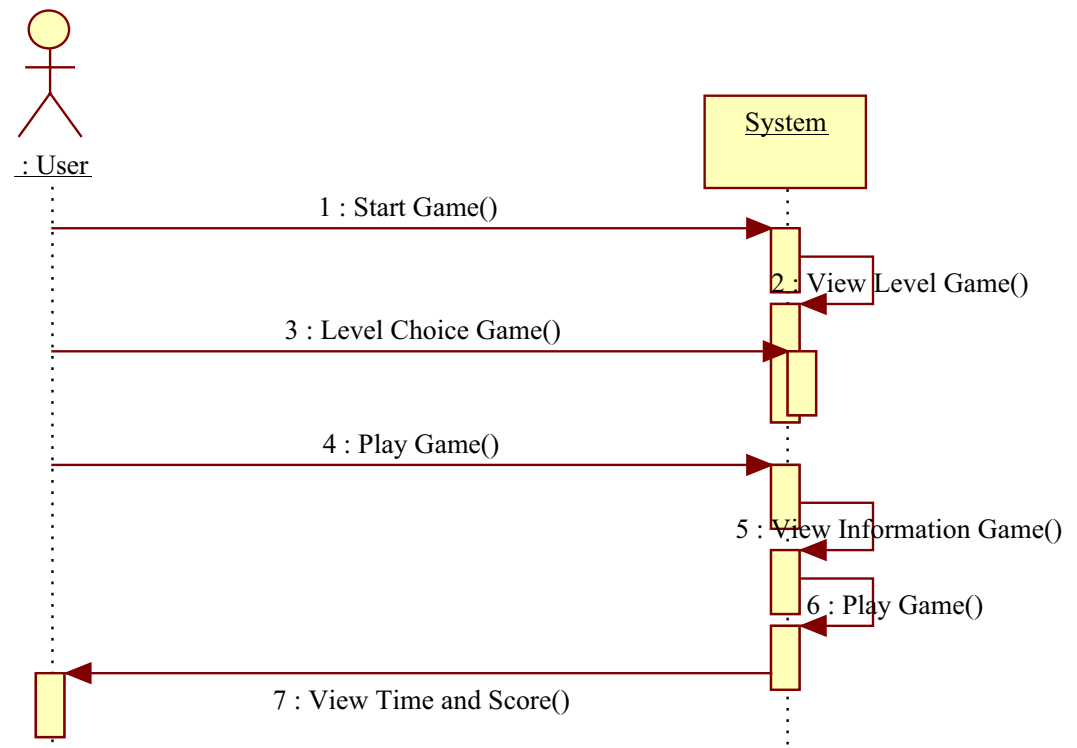

Fig. 3. Sequence diagram 


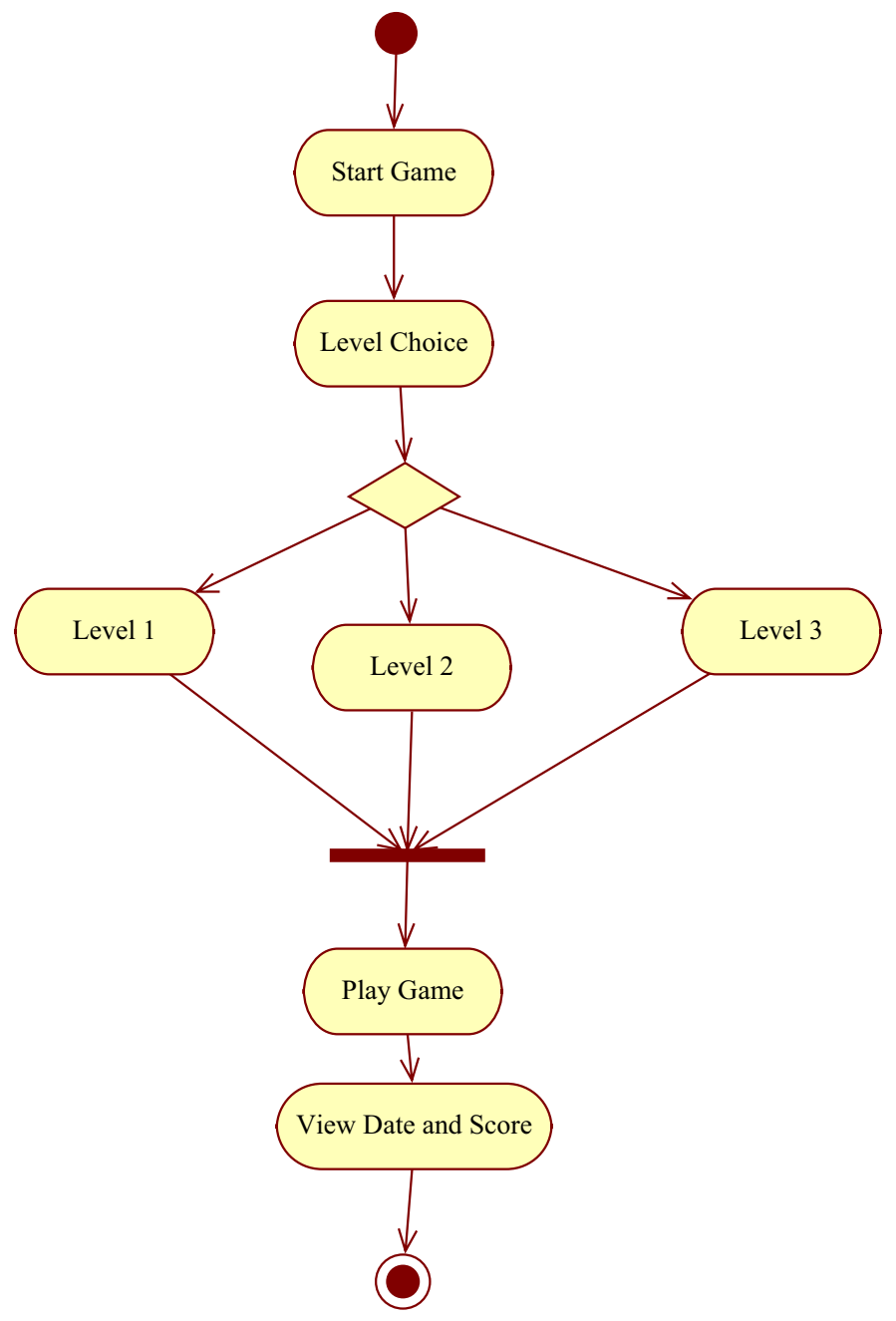

Fig. 4. Activity diagram

\section{$4 \quad$ Result and finding}

\subsection{Display system (Game)}

Figure 5 explains when opening the Makassar Flood Disaster Education Simulation Game application, the Start and Exit menu options will appear and Figure 6 shows when selecting the Start menu, the game level is displayed. 


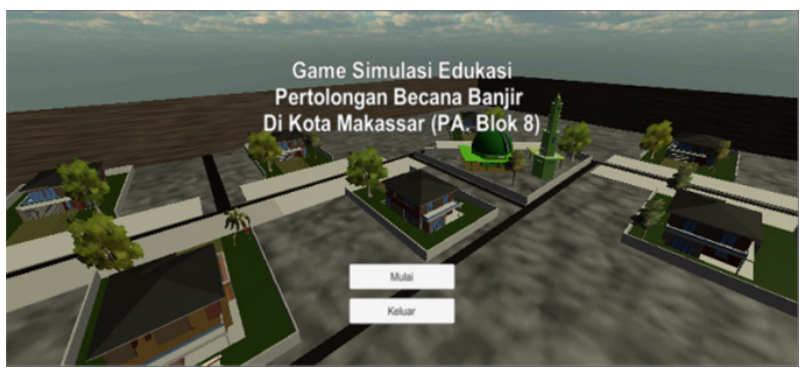

Fig. 5. Main menu

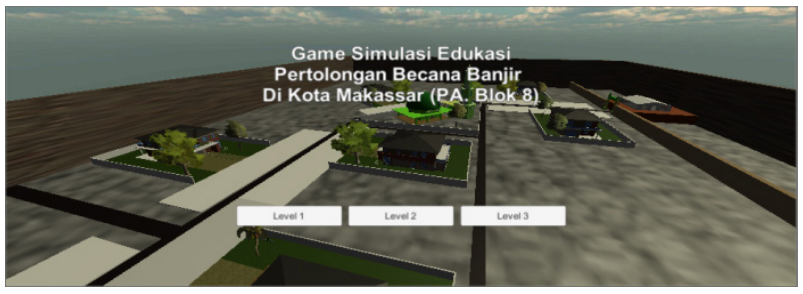

Fig. 6. Level geme menu

Figure 7 is a level 1 display; at this level, the water level is still ankle-high. In the game system, users can play games by securing essential items, namely turning off electric fuses, electronic items and other necessary items. Then important files.

Figure 8 is a level 2 game display; At level 2, the game's water level is already higher than level 1, and the rescue team has arrived.

Figure 9 shows level 3 in the game; at this level, it is in the post-flood stage, and the user plays the game by cleaning up after the flood.

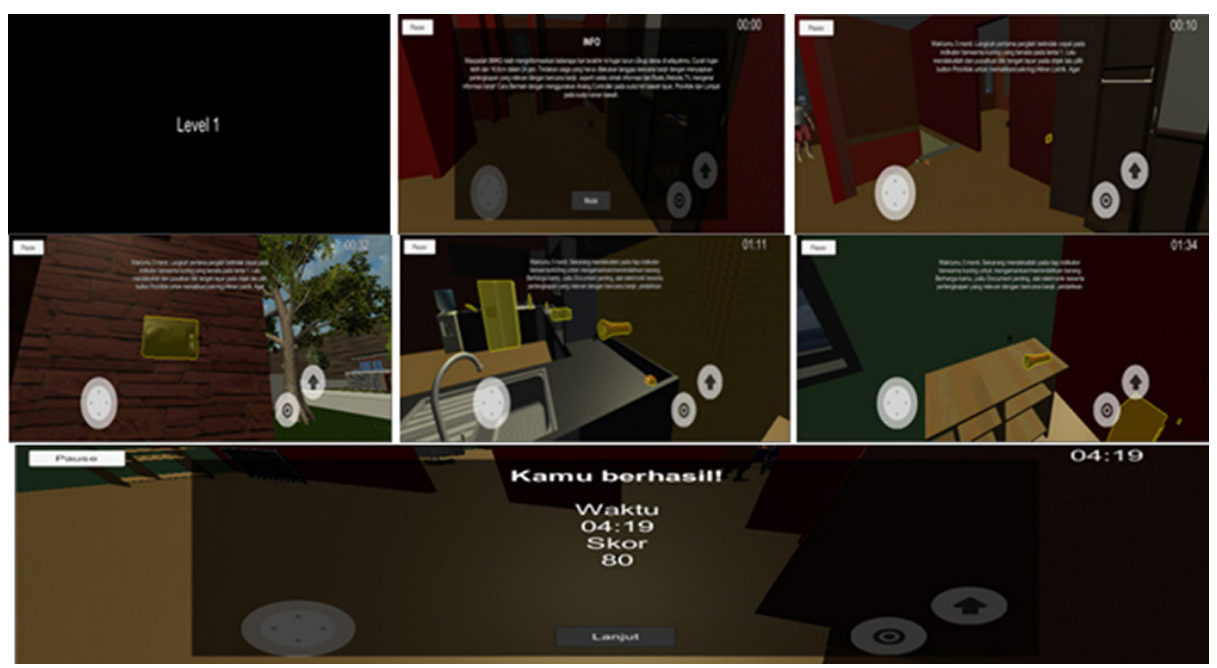

Fig. 7. Level 1 game 


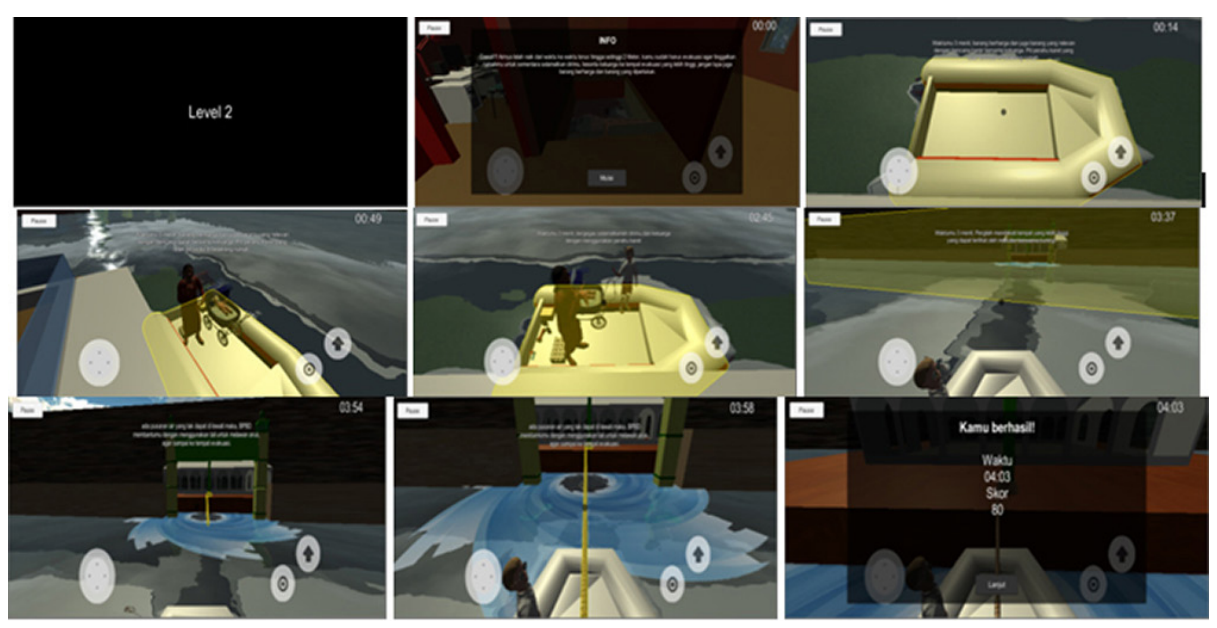

Fig. 8. Level 2 game
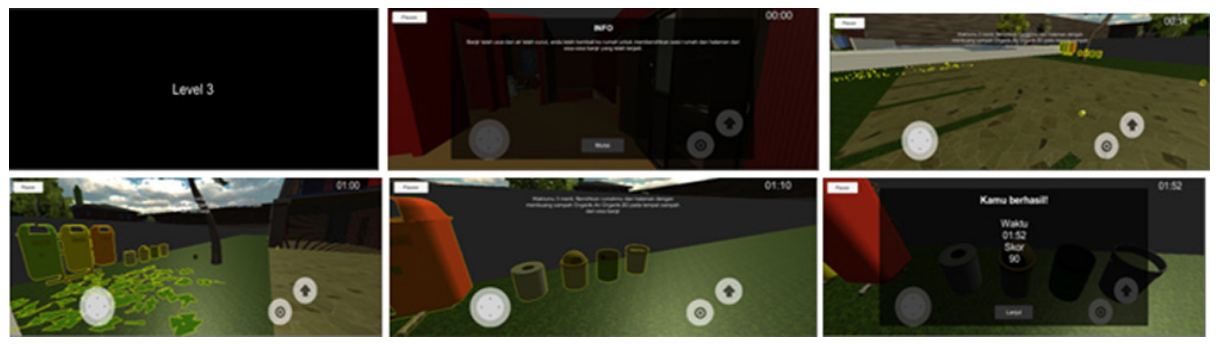

Fig. 9. Level 3 game

\subsection{Story line and scenario game}

One of the parameters for evaluating a good game application is if it has a storyline in it. This aims to strengthen the direction of the game in a game. In addition, the storyline in the gameplay will also provide instructions to players in the form of activities carried out in playing game applications. This game application tells about a situation/situation where a place/environment experiences a flood of catastrophic events. So the characters/players in this game must take steps to save themselves and their families and valuables and valuables from the situation.

Figure 10 is an overview of the overall game scenario and illustrates the steps for using the system. 


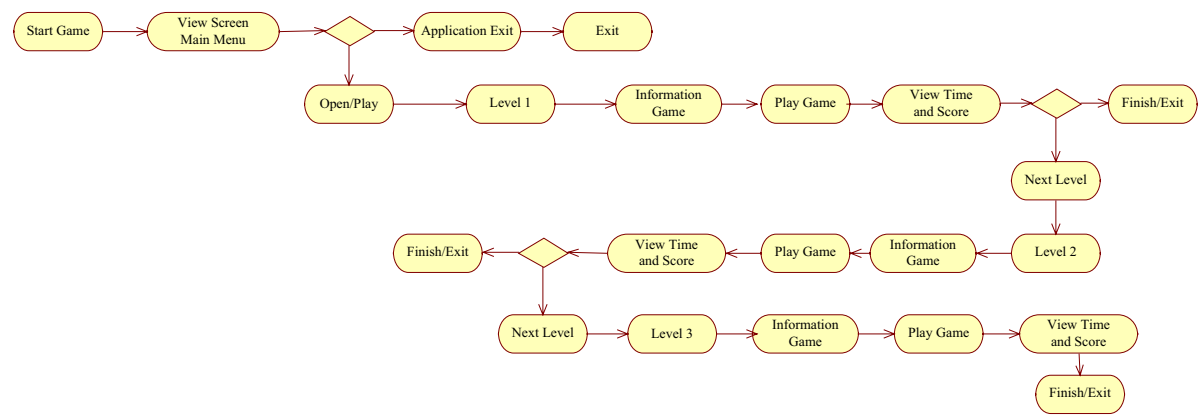

Fig. 10. Scenario game

\subsection{Testing}

Based on Black box testing that has been done in general, the results of application testing can be concluded as follows:

Table 1. Black box testing

\begin{tabular}{|l|l|l|}
\hline \multicolumn{1}{|c|}{ Testing Scenario } & \multicolumn{1}{|c|}{ Result } & Conclusion \\
\hline Click the Start button & Successfully Entered the Main page & Valid \\
\hline Level 1 Click & Enter Playing Game level 1 successfully & Valid \\
\hline $\begin{array}{l}\text { Pick Able Button on Bottom } \\
\text { Right Screen to Pick Up Object }\end{array}$ & Level 1 Successfully Moved Object & Valid \\
\hline $\begin{array}{l}\text { Pick Able Button on Bottom } \\
\text { Right Screen to pick up Object }\end{array}$ & Level 2 Successfully Displays Moving Objects & Valid \\
\hline $\begin{array}{l}\text { Continue level button and in next } \\
\text { Level Info }\end{array}$ & $\begin{array}{l}\text { Successfully Displayed information about game } \\
\text { level }\end{array}$ & Valid \\
\hline
\end{tabular}

Table 1 is a functional test of the design of an educational game system based on virtual reality in flood disaster management. The test text in Table 1 is based on the display of Figures 6, 7, 8 and 9, which have been tested based on the scenario of the designed game system.

Furthermore, to determine the usefulness of system users, evaluation questionnaires were distributed to fifty respondents consisting of various age groups ranging from children, adolescents and adults using the following formula:

$$
P=\frac{M}{N} \times 100 \%
$$

Information:

M: Number of respondents' answers to each question

$\mathrm{N}$ : Number of respondents

$\mathrm{P}$ : A percentage value

From the results of the questionnaire obtained the following results: 
Table 2. Average percentage

\begin{tabular}{|l|c|}
\hline \multicolumn{1}{|c|}{ Information } & Percentage \\
\hline Very Useful & $91,3 \%$ \\
\hline Useful & $5,2 \%$ \\
\hline Quite Useful & $3,5 \%$ \\
\hline Useless & $0 \%$ \\
\hline
\end{tabular}

Table 2 is the result of calculating the average percentage of twenty-five respondents, namely $91.3 \%$ said it was very useful, $5.2 \%$ was useful, $3.5 \%$ was quite useful, and $0 \%$ was not useful. More details can be seen in the following diagram.

Figure 11 describes the diagrammatic form of the questionnaire results that have been distributed to people who are often affected by floods in the city of Makassar. The diagram shows that the highest number is in the orange block diagram of $91.3 \%$, which states that it is very useful.

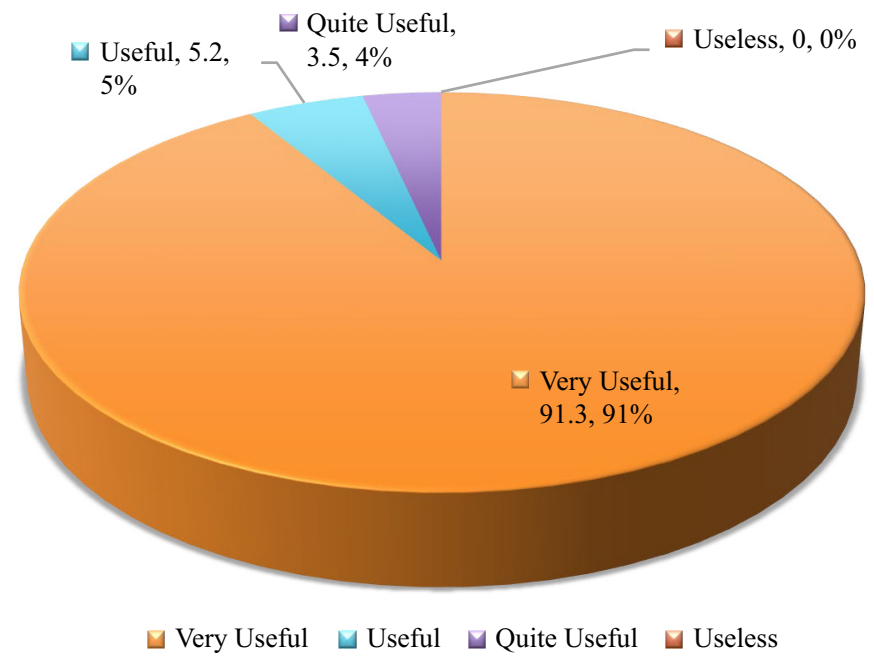

Fig. 11. Result questionare

\section{Conclusion}

This study concludes that this flood mitigation simulation system can help the people of Makassar understand what to do in the event of a flood. This virtual reality technology-based educational game gives a more attractive appearance to be excited and happy. Using educational games and educating the public to use educational game applications for flood disaster management simulations, helping people understand and respond to flood disasters. Based on black-box testing, valid results were obtained for all functional tests on the flood control educational game simulation system, especially in Makassar. Then based on the results of a questionnaire to determine the benefits of the system, obtained from fifty respondents consisting of children, adolescents and 
adults, the outcomes received $91.3 \%$ stated very useful, $5.2 \%$ useful, $3.5 \%$ quite useful, and $0 \%$ useless.

In the development of this research, it is recommended that the simulation system can later be added to the game level to the stage of seeking protection in the event of a flood disaster.

\section{Acknowledgement}

Thank you to DRPM RISTEK DIKTI Indonesia, which has provided funds for this research so that this research can be achieved and run smoothly, thanks also to the people of Makassar city who helped the author a lot in giving time to fill out questionnaires to meet the needs of the results of this research. Thanks to Dipa Makassar University for facilitating and assisting the author's administrative process during the study. Thanks also to all friends and family who helped a lot and all their understanding and to all parties involved in this research, either directly or indirectly, which the author cannot mention one by one.

\section{$7 \quad$ References}

[1] F. Edvardsen, Educational Games: Design, Learning, and Applications. Nova Science Publishers, 2010.

[2] Journal of Tropical Forest Science. Forest Research Institute Malaysia, 2003.

[3] G. C. Burdea and P. Coiffet, Virtual Reality Technology. John Wiley \& Sons, 2017.

[4] M.-C. Wen, M.-H. Tsai, S.-C. Kang, and Y.-L. Chang, "Feldouocadtigoanm1 E: An Alternative Approach for Disaster," p. 11, 2013.

[5] F. Argelaguet and C. Andujar, "A Survey of 3d Object Selection Techniques for Virtual Environments," Computers \& Graphics, vol. 37, no. 3, pp. 121-136, May 2013, doi: https:// doi.org/10.1016/j.cag.2012.12.003

[6] M.-H. Tsai, M.-C. Wen, Y.-L. Chang, and S.-C. Kang, "Game-Based Education for Disaster Prevention," AI \& Soc, vol. 30, no. 4, pp. 463-475, Nov. 2015, doi: https://doi.org/10.1007/ $\underline{\text { s00146-014-0562-7 }}$

[7] N. Petersen and D. Stricker, "Cognitive Augmented Reality," Computers \& Graphics, vol. 53, pp. 82-91, Dec. 2015, doi: https://doi.org/10.1016/j.cag.2015.08.009

[8] M. Barr, "Video Games Can Develop Graduate Skills in Higher Education Students: A Randomised Trial," Computers \& Education, vol. 113, pp. 86-97, Oct. 2017, doi: https://doi. org/10.1016/j.compedu.2017.05.016

[9] P. Praiwattana and A. El Rhalibi, "Game-Based Crisis Simulation and Generation Framework: Design and Implementation Structure," in E-Learning and Games, Cham, 2017, pp. 75-84. doi: https://doi.org/10.1007/978-3-319-65849-0_9

[10] Rismayani and A. Irmayana, "The Implementation of e-Learning into Mobile-Based Interactive Data Structure Subject," in 2017 5th International Conference on Cyber and IT Service Management (CITSM), Aug. 2017, pp. 1-5. doi: https://doi.org/10.1109/ CITSM.2017.8089234

[11] Q. Nan and M. Liang, "SubSafe-A Game-based Training System for Submarine Safety," presented at the 2018 Joint International Advanced Engineering and Technology Research Conference (JIAET 2018), Mar. 2018. doi: https://doi.org/10.2991/jiaet-18.2018.28 
[12] Q. Liu, Z. Cheng, and M. Chen, "Effects of Environmental Education on Environmental Ethics and Literacy Based on Virtual Reality Technology," The Electronic Library, vol. 37, no. 5, pp. 860-877, Jan. 2019, doi: https://doi.org/10.1108/EL-12-2018-0250

[13] G. Makransky, S. Borre-Gude, and R. E. Mayer, "Motivational and Cognitive Benefits of Training in Immersive Virtual Reality Based on Multiple Assessments," Journal of Computer Assisted Learning, vol. 35, no. 6, pp. 691-707, 2019, doi: https://doi.org/10.1111/ jcal.12375

[14] N. Mokhtar, A. Ismail, and Z. Muda, "Preliminary Study: Flood Awareness Training Preparation Using Serious Games," Asia-Pacific Journal of Information Technology and Multimedia, vol. 7, no. 2-2, Jan. 2019, Accessed: Dec. 08, 2019. [Online]. Available: http:// ejournals.ukm.my/apjitm/article/view/30182

[15] T. Weiss, A. Litteneker, C. Jiang, and D. Terzopoulos, "Position-based real-time simulation of large crowds," Computers \& Graphics, vol. 78, pp. 12-22, Feb. 2019, doi: https://doi. org/10.1016/j.cag.2018.10.008

[16] A. S. Adli and S. Rani, "Wasiban: Game Edukasi untuk Meningkatkan Kewaspadaan dan Kesiagaan Terhadap Banjir," AUTOMATA, vol. 1, no. 2, Art. no. 2, Jun. 2020, Accessed: Jun. 29, 2021. [Online]. Available: https://journal.uii.ac.id/AUTOMATA/article/view/15400

\section{Authors}

Rismayani is a lecture and researcher in the Department of Software Engineering, Dipa Makassar University, and Indonesian. Since 2014 until now has received research grants from SIMLITABMAS RISTEKDIKTI/BRIN Indonesia. Already have two patents registered with the Ministry of Law and Human Rights of the Republic of Indonesia and five copyright in the form of computer programs. From 2018 until now, she has been a reviewer in several national journals in Indonesia and reputable international journals. She also often fills in several events as a resource person (Email: rismayani@dipanegara.ac.id).

Alders Paliling is a lecturer in computer science at the University of Eleven Maret Kolaka Indonesia, with expertise in virtual reality, augmented reality and programming. $\mathrm{He}$ is also a practitioner in the field of computers (Email: palilingalders@gmail.com).

Asma Nurhidayani is a lecturer at Puangrimaggalatung University, Sengkang, Indonesia. She is a lecturer who focuses on management, business and education, and currently, she is an entrepreneur who already owns three well-known pharmacies in Sengkang, Indonesia. She also often fills in several events as a resource person (Email: pelangiasma@gmail.com).

Martina Pineng is a lecturer at Kristen Indonesia Toraja University, Toraja, Indonesia. She is a lecturer who focuses on telecommunications engineering, she is the head of Department of Electrical Engineering at Kristen Indonesia Toraja University, Indonesia. (Email: mpineng@gmail.com)

Article submitted 2021-10-23. Resubmitted 2021-12-22. Final acceptance 2021-12-23. Final version published as submitted by the authors. 